PHÂN TÍCH YẾU TỐ ẢNH HƯởNG ĐẾN NGHÈO TRONG CộNG ĐÔNG NGỦ DÂN VEN BIỂN TỈNH NINH THUẬN

\title{
ANALYZING FACTORS AFFECTING THE POVERTY IN FISHER COMMUNITIES IN NINH
} THUAN COAST

\author{
Phạm Hồng Mạnh \\ Truòng Đại hoc Nha Trang - phmanhdhnt@gmail.com \\ Phan Vĩnh An \\ Trưòng Cao đẳng nghề Ninh Thuận \\ (Bài nhận ngày 02 tháng 10 năm 2014, hoàn chỉnh sửa chữa ngày 14 tháng 01 năm 2015)
}

\section{TÓM TÄT}

Nghiên cứu này nhằm luợng hóa các yếu tố ảnh hương đến tình trạng nghèo trong cộng đồng ngu dân ven biển tỉnh Ninh Thuận. Bằng việc sử dụng lý thuyết về nghèo và mô hình kinh tế lương nhằm đánh giá mức độ ảnh hưởng của các yếu tố nghiên cứu tới tình trạng nghèo của hộ gia đình. Kết quả phân tích cho thấy tỉ lệ hộ nghèo trong cộng đồng ngu dân ven biển tỉnh Ninh Thuận còn khá cao ở mức 10,6\%. Nhũng yếu tố thực sư gây ra tình trạng nghèo cho hộ gia đình ngu dân ven biển tỉnh Ninh Thuận, bao gồm: thời gian đi học của chủ hộ, qui mô hộ gia đình, nghề luới kéo và múc độ giải thích của mô hình là 36,2\%. Kết quả nghiên cứu cũng chỉ ra rằng, để cho hộ có khả năng cải thiện tình trạng nghèo của mình, rất cần có nhũng chính sách về chuyển đổi nghề, giáo dục và đào tạo cũng nhu chính sách dân số và kế hoạch hóa gia đình trong cộng đồng ngu dân tại khu vục này.

Tù khóa: ngu dân, nghèo, Ninh Thuận.

\begin{abstract}
This study aims to quantify factors affecting the poverty in fisher communities in the coast of Ninh Thuan province. Based on theories on poverty, we employed an econometric model to estimate the impact of each factor on the poverty of the households. We found that the rate of poor households remains high, at 10.6\%. Factors causing the poverty include householder's years of schooling, family size, and net fishing business. The model's explanatory capacity is $36.2 \%$. The results also show that in order to successfully combat the poverty, it is necessary to introduce career transition assistance policies, education and training as well as family planning to the fisher households.
\end{abstract}

Key words: Fishers, poverty, Ninh Thuan.

\section{1. Đặt vấn đề}

Ninh Thuận là một tỉnh ven biển thuộc vùng Duyên hải Nam Trung Bộ của Việt Nam. Trung tâm của tỉnh là thành phố Phan Rang Tháp Chàm nằm cách Thành phố Hồ Chí Minh khoảng $350 \mathrm{~km}$ về phía Nam, cách Nha Trang $105 \mathrm{~km}$, cách Đà Lạt $110 \mathrm{~km}$ đồng thời nằm cách sân bay Cam Ranh khoảng 60 km, thuận tiện cho việc giao lưu phát triển kinh tế xã hội của tỉnh. Nghèo đói đang giảm nhanh tại tỉnh Ninh Thuận. Theo các số liệu thống kê chính thức, mức sống của người dân địa phương đã được cải thiện (UBND tỉnh Ninh Thuận, 2013a). Các yếu tố chủ yếu tạo ra thay đổi này chủ yếu là hoạt động kinh tế gia tăng, cơ sở hạ

\section{Trang 46}


tầng tốt hơn, người dân tiếp cận tốt hơn các dịch vụ y tế và giáo dục cũng như các lợi ích khác do các chương trình giảm nghèo hiện nay mang lại. Tuy vậy, Ninh Thuận vẫn là một tỉnh nghèo của cả nước, xếp thứ 39/63 tỉnh thành về mức độ nghèo và là tỉnh nghèo nhất vùng Đông Nam Bộ (UBND tỉnh Ninh Thuận, 2013a).

Trong địa bàn Ninh Thuận hiện nay, khu vực có tỉ lệ hộ nghèo cao vẫn thuộc về khu vực ngư dân ven biển Ninh Thuận. Để có thể giảm nghèo nhanh hơn cho người dân thuộc khu vực này vẫn đang là những bài toán đặt ra cho chính quyền địa phương nơi đây.

Từ nhiều năm qua, vấn đề đói nghèo đã thu hút được nhiều sự quan tâm của các địa phương, các nhà khoa học. Những công trình nghiên cứu tiêu biểu phải kể đến như: Nghiên cứu của WB (2009), nghiên cứu của Nguyễn Trọng Hoài và đồng nghiệp (2008) hay gần đây là những nghiên cứu của Phạm Hồng Mạnh (2011, 2012)... Tất cả những nghiên cứu trên đã góp phần hình thành cơ sở khoa học trong việc phân tích về tình trạng nghèo của hộ gia đình, đặc biệt là gia đình ngư dân ven biển ở Việt Nam hiện nay. Tuy vậy, những đánh cụ thể và chi tiết về đặc điểm nghèo tại cộng đồng ngư dân ven biển tỉnh Ninh Thuận vẫn chưa được làm rõ.

Xuất phát từ những đặc điểm và thực tiễn trên, mà bài viết này sẽ tiếp tục kế thừa những nghiên cứu trước để đánh giá tình trạng đói nghèo trong cộng đồng ngư dân ven biển tỉnh Ninh Thuận nhằm đưa ra những giải pháp giảm nghèo cho ngư dân tại khu vực này.

\section{Cơ sở lý thuyết và mô hình nghiên cứu \\ Khái niệm nghèo}

Nghèo là một khái niệm đa chiều, do đó chưa có một khái niệm thống nhất nào. Theo Ngân hàng thế giới (WB) nghèo là tình trạng không có khả năng có mức sống tối thiểu. Với cách đánh giá này thì điểm khởi đầu để xác định ranh giới đói nghèo là nhu cầu kcalo (năng lượng) tối thiểu được dùng cho mỗi người mỗi ngày. Mức tối thiểu mà WB sử dụng là $2100 \mathrm{kcalo} /$ người/ngày với rổ lương thực thực phẩm gồm 40 sản phẩm. Ngân hàng Thế giới gọi đây là chỉ số phúc lợi - thước đo chất lượng cuộc sống và được biểu hiện ở mức thu nhập hay mức chi tiêu của hộ gia đình. Trong nghiên cứu và thu thập thông tin, Ngân hàng Thế giới dựa trên số liệu về chi tiêu là chính vì cho rằng thu nhập, bản thân nó không phản ánh trực tiếp chất lượng cuộc sống như là chi tiêu, và hơn nữa các hộ gia đình do nhiều lý do thường kê khai không đầy đủ thu nhập. Do đó, chuẩn nghèo (nghèo tuyệt đối) mà Ngân hàng thế giới đưa ra cho các nước đang phát triển là $1,25 \$$ ngày và các nước phát triển là $2 \$$ ngày theo sức mua tương đương (World Bank, 2014).

Tại Việt Nam, nghèo được thừa nhận theo khái niệm của Ủy ban kinh tế - Xã hội khu vực châu Á - Thái Bình Dương tổ chức ở Thái Lan năm 1993 đó là: nghèo đói là tình trạng một bộ phận dân cư không có khả năng thỏa mãn những nhu cầu cơ bản của con người mà những nhu cầu ấy phụ thuộc vào trình độ phát triển kinh tế - xã hội, phong tục tập quán của từng vùng và những phong tục ấy được xã hội thừa nhận (Chính phủ, 2003). Xuất phát từ trình độ phát triển thực tế tại Việt Nam, Chính phủ Việt Nam đã xây dựng mức chuẩn nghèo quốc gia cho giai đoạn 2011 - 2015. Theo quy định của Chính Phủ, tại khu vực nông thôn những hộ có thu nhập trung bình tháng là từ 400 nghìn đồng/người được coi là hộ nghèo (Chính phủ, 2011). Chính vì vậy, trong nghiên cứu sử dụng khái niệm và mức chuẩn nghèo quốc gia trong giai đoạn này để làm tiêu chí đánh giá nghèo đói. 


\section{Các yếu tố ảnh hưởng đến tình trạng nghèo của hộ gia đình}

Các công trình nghiên cứu trước đây đã nhận diện về các yếu tố ảnh hưởng tới tình trạng nghèo của hộ gia đình, như: Nghiên cứu của Jonathan Houghton, Dominique và các tác giả khác (1999), Jonathan Haughton, Shahidur R. Khader (2009), Nguyễn Trọng Hoài và đồng nghiệp (2006), Phạm Hồng Mạnh (2011a, 2011b), Đinh Phi Hổ (2013)... Từ những nghiên cứu thực nghiệm của các quốc gia trên thế giới, Ngân hàng Thế giới (World Bank, 2005; Jonathan Haughton, Shahidur R. Khader, 2009) đã xác định các nhóm yếu tố cơ bản ảnh hưởng tới tình trạng nghèo của hộ bao gồm:

Thứ nhất, nhóm nhân tố liên quan đến đặc điểm vùng bao gồm: sự cách biệt về địa lý/xã hội do thiếu hạ tầng cơ sở; hạn chế trong việc tiếp cận các loại thị trường và các dịch vụ xã hội, nguồn lực cơ bản như đất đai và chất lượng đất đai, điều kiện tự nhiên (thời tiết...), quản lý nhà nước và bất bình đẳng.

Thứ hai, nhóm nhân tố liên quan đến đặc điểm của cộng đồng bao gồm: hạ tầng cơ sở (điện, nước, đường giao thông... ), phân bổ đất đai, khả năng tiếp cận các hàng hóa và dịch vụ công (y tế, giáo dục).

Thứ ba, nhóm nhân tố liên quan đến những đặc điểm của hộ gia đình như: qui mô hộ gia đình, tỷ lệ phụ thuộc (phần trăm số người trưởng thành không có hoạt động tạo thu nhập), giới tính của chủ hộ, tài sản của hộ gia đình: đất đai, phương tiện sản xuất, nhà cửa..., tỷ lệ có việc làm của những thành viên trưởng thành trong hộ, loại việc làm chính, tự làm hay làm thuê và theo nguồn thu nhập chính của hộ... trình độ học vấn trung bình của hộ.

Thứ tư, những đặc điểm của chủ hộ: tuổi, giáo dục (số năm đi học, bằng cấp cao nhất), việc làm (tình trạng việc làm, loại công việc), dân tộc (có hay không có thuộc nhóm dân tộc thiểu số).

Như vậy, biến số nghèo của hộ gia đình là một hàm phụ thuộc vào nhiều yếu tố. Các nhóm yếu tố ảnh hưởng tới tình trạng nghèo bao gồm: đặc điểm vùng, đặc điểm của cộng đồng, đặc điểm của hộ gia đình, đặc điểm của chủ hộ.

Trong nghiên cứu này, những biến số đặc trưng của hộ gia đình ngư dân tại vùng ven biển tỉnh Ninh Thuận được sử dụng để đánh giá khả năng rơi vào tình trạng nghèo bao gồm: đặc điểm về chủ hộ gia đình như: giới tính, tuổi, tình trạng sức khỏe, trình độ học vấn, kinh nghiệm của chủ hộ trong hoạt động khai thác. Đặc điểm về hộ gia đình, bao gồm: qui mô hộ, đặc điểm nghề khai thác, số tháng khai thác, công suất tàu thuyền, tiếp cận đất sản xuất, tiếp cận tín dụng, nghề làm thêm. Ngoài ra, đặc điểm từ góc độ cộng đồng như: đường giao thông, khoảng cách từ hộ đến chợ trung tâm... cũng được xem xét.

\section{Phương pháp nghiên cứu \\ Mẫu nghiên cứu}

Đối tượng nghiên cứu là vấn đề nghèo đói cũng như các yếu tố ảnh hưởng tới đói nghèo trong cộng đồng ngư dân. Đối tượng khảo sát là những hộ gia đình ngư dân trong cộng đồng ngư dân ven biển tỉnh Ninh Thuận tập trung vào những hộ làm nghề khai thác hải sản thời gian từ tháng 06 năm 2013 đến tháng 12 năm 2013.

Nghiên cứu đã tiến hành khảo sát các hộ ngư dân ven biển tại Ninh Thuận bằng phương pháp lấy mẫu định mức (quota sampling) dựa trên tỉ lệ tổng thể tàu thuyền khai thác ven bờ của mỗi địa phương trong tỉnh. Số lượng mẫu điều tra là 300 hộ gia đình ngư dân hoạt động khai thác hải sản tại các địa phương của Ninh Thuận. Trong 300 phiếu điều tra được khảo sát, số

\section{Trang 48}


phiếu thu về 214 phiếu được sử dụng vào việc phân tích.

\section{Mô hình kinh tế lượng về yếu tố tác động đến tình trạng nghèo của hộ}

Trong nghiên cứu cứu này, một mô hình hồi qui logit được sử dụng để phân tích các yếu tố ảnh hưởng đến tình trạng nghèo của hộ gia đình, đồng thời sử dụng mức chuẩn nghèo theo qui định của Chính Phủ đối với khu vực nông thôn giai đoạn 2011 - 2015 làm tiêu chí đánh giá nghèo đói (Chính Phủ (2011). Từ cơ sở lý thuyết đã nêu, mô hình kinh tế lượng về yếu tố tác động đến tình trạng nghèo của hộ ngư dân tại vùng ven biển Ninh Thuận được thể hiện như sau:

$L n\left[\frac{P(Y=1)}{P(Y=0)}\right]=\beta_{0}+\beta_{1} T U O I+\beta_{2} G I O I T I N H+\beta_{3} K I N H_{-} C H+\beta_{4} H O C V A_{-} C H+\beta_{5} Q U I M O+\beta_{6} D U O N G_{-} G T+\beta_{7}$ KC $\_C H O+$ $+\beta_{8} S U C_{-} K H+\beta_{9} N G H E_{-} K E O+\beta_{10} S O T H A_{-} K T+\beta_{11} C S U A T \_T A+\beta_{12} C O D A T+\beta_{13} C O V A Y+\beta_{14} L A M \_T H E+\varepsilon$

Trong đó:

Y là biến biến phụ thuộc $(\mathrm{Y}=1$, nếu thuộc hộ nghèo; $\mathrm{Y}=0$ nếu những trường hợp khác)

TUOI: Biến số tuổi tính từ năm sinh của chủ hộ. Kỳ vọng mang dấu dương $(+)$. Cũng theo kết quả điều tra mức sống dân cư và kết quả của các công trình nghiên cứu nghèo đói khác như của Nguyễn Trọng Hoài và đồng nghiệp (2006), Phạm Hồng Mạnh (2012)... cho rằng tuổi của chủ hộ sẽ đồng biến với kinh nghiệm trong hoạt động sản xuất nghề khai thác và tác động tích cực đến thu nhập, từ đó giảm thiểu khả năng rơi vào ngưỡng nghèo của hộ. Trong nghiên cứu, biến số này được giả định là tuổi của chủ hộ có quan hệ ngược chiều với khả năng rơi vào ngưỡng nghèo.

GIOITINH: là biến giả, nhận giá trị 1 nếu chủ hộ là nam giới, nhận giá trị 0 cho trường hợp chủ hộ thuộc nữ giới, kỳ vọng dấu hệ số hồi quy (-). Do đặc tính nghề nghiệp khai thác thủy sản nên thường phù hợp với lao động nam hơn, vì vậy nghiên cứu kỳ vọng nếu chủ hộ là nam sẽ làm giảm xác suất nghèo của hộ.

KINH_CH: thể hiện số năm tham gia hoạt động khai thác của hộ gia đình, kỳ vọng mang dấu (-). Những hộ gia đình có thời gian hoạt động trong nghề khai thác càng lâu năm thường có thu nhập ổn định và cao hơn những hộ gia đình mới tham gia. Do đó, nghiên cứu kỳ vọng rằng nếu các yếu tố khác không đổi, việc tăng thêm 1 năm kinh nghiệm sẽ làm giảm xác suất rơi vào tình trạng nghèo của hộ.

HOCVA_CH: thể hiện số năm đi học trung bình của chủ hộ, kỳ vọng mang dấu dương (-). Khi trình độ học vấn của chủ hộ trong gia đình càng cao, càng có khả năng tiếp cận với công nghệ, kỹ thuật trong sản xuất và có điều kiện để nâng cao cơ hội cải thiện thu nhập. Do đó nghiên cứu kỳ vọng rằng, nếu các yếu tố khác không đổi, việc tăng thêm 1 đơn vị của biến này sẽ làm giảm xác suất rơi vào tình trạng nghèo của hộ.

QUYMO: Biến thể hiện số người sống trong một hộ, không tính đến người làm thuê và ở nhờ. Kỳ vọng mang dấu $(+)$. Theo điều tra mức sống dân cư của Tổng cục thống kê phối hợp với UNDP cho thấy những bằng chứng đó là, những hộ gia đình nông thôn đông con, ít có điều kiện chăm sóc sức khỏe và học hành, vì vậy khả năng tiếp cận thị trường lao động thấp và khả năng rơi vào tình trạng nghèo cao hơn so với những hộ khác. Vì vậy, nghiên cứu giả định rằng qui mô hộ có mối quan hệ đồng biến với xác suất rơi vào ngưỡng nghèo.

DUONG_GT: là biến phản ánh tình trạng tiếp cận cơ sở hạ tầng, nhận giá trị 1 nếu khu vực hộ gia đình sinh sống có đường giao thông được rải nhựa hoặc xi măng và bằng không cho 
những trường hợp còn lại, kỳ vọng dấu hệ số hồi quy (-). Nhiều bằng chứng thực nghiệm đã cho thấy, các khu vực dân cư có đường giao thông nông thôn thuận lợi sẽ góp phần rất lớn trong việc lưu thông, trao đổi hàng hóa và tiếp cận thị trường và có nhiều điều kiện trong việc cải thiện thu nhập. Chính vì vậy, trong nghiên cứu giả định rằng, những hộ gia đình tiếp cận dễ dàng với hạ tầng cơ sở thiết yếu trên sẽ có xác xuất rơi vào nghèo đói thấp hơn so với các hộ khác.

KC_CHO: biến số khoảng cách chợ là biến số khoảng cách tính từ nhà chủ hộ đến trung tâm chợ. Kỳ vọng mang dấu (-). Hộ gia đình có khoảng cách gần chợ thường thuận tiện trong cuộc sống sinh hoạt hàng ngày, tăng khả năng tiêu thụ sản phẩm và giảm bớt chi phí đi lại. Trong nghiên cứu, biến số này được giả định là khoảng cách từ nhà của chủ hộ đến trung tâm chợ có quan hệ ngược chiều với khả năng rơi vào ngưỡng nghèo.

SUC_KH: là biến giả, nhận giá trị 1 nếu chủ hộ có vấn đề về sức khỏe, nhận giá trị 0 nếu những trường hợp khác, kỳ vọng mang dấu dương $(+)$. Những chủ hộ có vấn đề về sức khỏe thường ít có khả năng lao động và vì vậy thường không có khả năng để tạo ra thu nhập. Trong nghiên cứu, biến số này được giả định có quan hệ thuận chiều với khả năng rơi vào ngưỡng nghèo.

NGHE_KEO: là biến thể hiện hộ gia đình hoạt động trong nghề lưới kéo. Trong các nghề khai thác chủ yếu, nghề lưới kéo được ngư dân sử dụng khá phổ biến do đặc điểm của nghề này thường khai thác tận diệt. Mặc dù Chính phủ đã có qui định cấm khai thác nghề này tại khu vực ven bờ, nhưng do sản lượng khai thác của nghề này thường lớn nên rất nhiều ngư dân tại vùng ven biển Ninh Thuận vẫn hoạt động lén lút. Chính vì vậy, trong nghiên cứu giả định rằng, những hộ hoạt động trong nghề lưới kéo thường có thu nhập cao hơn so với các nghề khai thác khác, và điều này rất cần được kiểm định trong mô hình nghiên cứu đối với các hộ ngư dân tại khu vực này.

SOTHAKTH: là biến thể hiện thời gian khai thác trong năm của hộ, kỳ vọng hệ số hồi quy (-). Nếu chủ hộ làm nghề khai thác quanh năm, sẽ cho thu nhập cao hơn khai thác theo mùa vụ hoặc có thời gian nghỉ không khai thác trong năm. Do đó kỳ vọng nếu các yếu tố khác không đổi, việc tăng 1 đơn vị của biến này sẽ làm giảm xác suất rơi vào ngưỡng nghèo của hộ.

CSUAT_TA: là biến thể hiện tình trạng hộ có tàu hoặc ghe máy hay không, nhận giá trị 1 nếu có tàu hoặc ghe bằng máy, nhận giá trị 0 cho những trường hợp khác, kỳ vọng hệ số hồi quy (-), nghiên cứu giả định rằng những hộ có tàu ghe máy sẽ có khả năng khai thác cao hơn đối với những hộ không có, và vì vậy sẽ cho sản lượng khai thác cao hơn, do đó nếu trong nghiên cứu giả định, những hộ có tàu ghe máy sẽ làm giảm xác suất nghèo của hộ.

CODAT: là biến thể hiện sự phân bố đất sản xuất đến hộ gia đình, kỳ vọng của biến này mang dấu dương (-). Theo Phạm Hồng Mạnh (2012), những hộ ngư dân hầu hết đều sinh sống chủ yếu tại các vùng ven biển và thường ít hộ có đất trong sản xuất nông nghiệp. Nếu những hộ ngư dân có đất canh tác thêm trong nông nghiệp thì có nhiều điều kiện để gia tăng thu nhập. Vì vậy, nghiên cứu này giả định rằng hộ có đất để trồng trọt và canh tác sẽ có khả năng làm giảm xác suất nghèo.

COVAY: là biến dummy thể hiện tình trạng tiếp cận nguồn vốn chính thức của hộ, nhận giá trị 0 nếu hộ không được vay, kỳ vọng mang dấu (-). Nhiều nghiên cứu gần đây đã cho thấy rằng khi các hộ gia đình tiếp cận được với các nguồn tín dụng chính thức để đầu tư vào hoạt động sản xuất sẽ có nhiều cơ hội để mở rộng hoạt động sản xuất của mình và có điều kiện để gia tăng thu nhập. Do vậy, nghiên cứu giả định

\section{Trang 50}


rằng những hộ tiếp cận được với tín dụng chính thức có khả năng giảm xác suất rơi vào ngương nghèo.

LAMTHEM: là biến giả, thể hiện hộ gia đình hoạt động trong nghề cá, nhận giá trị 1 nếu chủ hộ có làm thêm các ngành nghề khác và bằng 0 nếu hộ chỉ tham gia hoạt động khai thác hải sản, kỳ vọng của biến số này trong mô hình mang dấu âm (-). Thực tiễn kết quả điều tra cho thấy những ngư dân chỉ hoạt động nghề cá thuần túy sẽ có nhiều khả năng rơi vào ngưỡng nghèo. Do đó nghiên cứu giả định rằng nếu hộ có nhiều hoạt động khác nhau ngoài khai thác thủy sản ven bờ sẽ có điều kiện để tạo thêm thu nhập và vì vậy xác suất giảm nghèo lớn hơn.

$\varepsilon$ : là sai số ngẫu nhiên của hàm hồi qui tổng thể

Để đánh giá tác động biên của các yếu tố đến tình trạng nghèo của hộ gia đình ngư dân ven biển tại Ninh Thuận, từ mô hình (1), có thể khái quát mô hình hồi logit thức tổng quát như sau:

$$
\operatorname{Ln}\left[\frac{P(Y=1)}{P(Y=0)}\right]=\beta_{0}+\beta_{1} X_{1}+\beta_{2} X_{2}+\ldots+\beta_{k} X_{k}
$$

Trong đó,

$\mathbf{P}(\mathbf{Y}=\mathbf{1})=\mathbf{P}_{\mathbf{0}}$ là khả năng xảy ra (xác suất) hộ nghèo

$\mathbf{P}(\mathbf{Y}=\mathbf{0})=\mathbf{1}-\mathbf{P}_{\mathbf{0}}$ là khả năng xảy ra (xác suất) hộ không nghèo.

Gọi hệ số Odd:

$\boldsymbol{O}_{\mathbf{0}}=\frac{P_{0}}{1-P_{0}}=\frac{P(\text { ngheo })}{P(\text { khong ngheo })}$ là hệ số chênh lệch nghèo ban đầu, trong đó $\mathbf{P}_{0}$ là xác suất nghèo ban đầu.

Do vậy: $O_{0}=\frac{P_{0}}{1-P_{0}}=e^{\beta_{0}+\beta_{1} X_{1}+\ldots+\beta_{k} X_{k}}$
Giả định rằng các yếu tố khác không thay đổi, khi tăng $X_{\mathrm{k}}$ lên 1 đơn vị, hệ số chênh lệch nghèo mới $\left(\mathrm{O}_{1}\right)$ sẽ là:

$$
\begin{aligned}
O_{1}= & \frac{P_{1}}{1-P_{1}}=e^{\beta_{0}+\beta_{1} X_{1}+\ldots+\beta_{k}\left(X_{k}+1\right)} \\
= & e^{\beta_{0}+\beta_{1} X_{1}+\ldots+\beta_{k} X_{k}+\beta_{k}} \\
= & e^{\beta_{0}+\beta_{1} X_{1}+\ldots+\beta_{k} X_{k}} \times e^{\beta_{k}}
\end{aligned}
$$

Suy ra:

$$
O_{1}=\frac{P_{1}}{1-P_{1}}=\frac{P_{0}}{1-P_{0}} \times \varepsilon^{\beta_{k}}
$$

Công thức trên có thể được viết lại như sau:

$$
\begin{gathered}
\frac{P_{1}}{1-P_{1}}=O_{0} \times \varepsilon^{\beta_{k}} \\
\text { Do đó: } \\
P_{1}=\frac{O_{0} \times \varepsilon^{\beta_{k}}}{1+O_{0} \times \varepsilon^{\beta_{k}}}
\end{gathered}
$$

Thế hệ số Odd vào phương trình trên, ta được:

$$
P_{1}=\frac{P_{0} \times e^{\beta_{k}}}{1-P_{0}\left(1-e^{\beta_{k}}\right)}
$$

Công thức trên có ý nghĩa rằng với các yếu tố khác cố định, khi yếu tố $\mathrm{X}_{\mathrm{k}}$ tăng lên một đơn vị thì xác suất nghèo của một hộ gia đình sẽ chuyển dịch từ $\mathrm{P}_{0}$ sang $\mathrm{P}_{1}$. Với cách triển khai như vậy chúng ta có thể mô tả những kịch bản cho các yếu tố ảnh hưởng đến khả năng mà một hộ rơi vào ngưỡng nghèo và từ đó có thể định lượng được các tác động đến sự thay đổi các yếu tố ảnh hưởng để làm giảm xác suất một hộ rơi vào ngưỡng nghèo.

Từ kết quả phân tích tỉ lệ nghèo trong cộng đồng ngư dân ven biển Ninh Thuận hiện tại và từ công thức (3) sẽ tính toán được các kịch bản xảy ra xunh quanh tỉ lệ nghèo này để có thể thấy rõ hơn việc thay đổi các yếu tố khác nhau làm tăng hay giảm tỉ lệ nghèo trong cộng đồng ngư dân này. 


\section{Kết quả nghiên cứu và thảo luận}

\subsection{Khái quát về mẫu nghiên cứu}

Nghiên cứu đã thu thập thông tin từ 300 hộ ngư dân. Sau khi loại các phiếu không đạt yêu cầu như không điền đầy đủ thông tin, sai đối tượng nghiên cứu, số liệu thống kê không có tính đại diện trong mẫu... số phiếu đạt chất lượng sử dụng cho phân tích là 214 phiếu. Các đặc điểm về nhân khẩu học và đặc điểm kinh tế - xã hội của hộ gia đình ngư dân được thể hiện qua Bảng 1.
Kết quả điều tra cho thấy, hầu hết chủ hộ ngư dân là nam giới (chiếm 82,2\%), tập trung ở độ tuổi từ 33 đến 52 (chiếm $68,7 \%$ ) và có trình độ văn hóa thấp. Số chủ hộ có trình độ học vấn từ mù chữ đến học hết cấp hai chiếm 90,2\%. Trong số những hộ được điều tra hầu hết chưa được đào tạo nghề một cách bài bản và chỉ có số ít chủ hộ đã được đào tạo nghề nghiệp. Số hộ có bằng cấp chuyên môn trung học chuyên nghiệp, học nghề, cao đẳng, đại học chỉ chiếm $5,6 \%$ số hộ được điều tra.

Bảng 1. Đặc điểm của chủ hộ gia đình ngư dân

\begin{tabular}{|l|c|c|c|c|c|}
\hline \multicolumn{1}{|c|}{ Độ tuổi } & $\begin{array}{c}\text { Số lượng } \\
(\mathbf{H o ̣})\end{array}$ & Tỷ lệ $\mathbf{( \% )}$ & Trình độ học vấn & $\begin{array}{c}\text { Số lượng } \\
\text { (Hộ) }\end{array}$ & Tỷ lệ $\mathbf{( \% )}$ \\
\hline Dưới 32 tuổi & 33 & 15,4 & Không đi học & 35 & 16,4 \\
\hline Từ 33 đến 42 & 68 & 31,8 & Cấp 1 & 76 & 35,5 \\
\hline Từ 43 đến 52 & 79 & 36,9 & Cấp 2 & 82 & 38,3 \\
\hline Trên 53 & 34 & 15,9 & Cấp 3 & 21 & 9,8 \\
\hline \multicolumn{1}{|c|}{ Tổng } & $\mathbf{2 1 4}$ & $\mathbf{1 0 0}$ & Tổng & $\mathbf{2 1 4}$ & $\mathbf{1 0 0}$ \\
\hline
\end{tabular}

Nguồn: Tác giả tính toán tù số liệu điều tra

Hầu hết các hộ gia đình ngư dân ven biển tỉnh Ninh Thuận có quy mô hộ gia đình lớn. Theo kết quả điều tra, có $97,7 \%$ hộ gia đình có số người trong gia đình từ 3 thành viên trở lên, chỉ có $2,3 \%$ hộ gia đình có số người từ hai trở xuống. Bên cạnh đó, kết quả điều tra được thể hiện ở Bảng 2 cho thấy, có $10,3 \%$ hộ có mức thu nhập bình quân đầu người thuộc diện hộ nghèo (có thu nhập từ 400.000 đồng trở xuống), 5,6\% hộ cận nghèo (có thu nhập từ trên 400.000 đồng đến 520.000 đồng) và $2,3 \%$ hộ khó khăn (có thu nhập từ trên 520.000 đồng đến 600.000 đồng).

Bảng 2. Thu nhập bình quân đầu người và qui mô hộ gia đình

\begin{tabular}{|l|c|c|c|c|c|}
\hline \multicolumn{1}{|c|}{$\begin{array}{c}\text { Thu nhập } \\
\text { (nghìn đồng/người/tháng) }\end{array}$} & $\begin{array}{c}\text { Số } \\
\text { lượng } \\
\text { (hộ) }\end{array}$ & $\begin{array}{c}\text { Tỷ lệ } \\
(\mathbf{\%})\end{array}$ & $\begin{array}{c}\text { Qui mô hộ gia đình } \\
\text { (người) }\end{array}$ & $\begin{array}{c}\text { Số } \\
\text { lượng } \\
\text { (hộ) }\end{array}$ & $\begin{array}{c}\text { Tỷ lệ } \\
(\mathbf{\%})\end{array}$ \\
\hline Từ 400 trở xuống & 22 & 10,3 & Từ 2 người trở xuống & 5 & 2,3 \\
\hline Từ trên 400 đến 520 & 12 & 5,6 & Từ 3 đến 4 người & 92 & 43,0 \\
\hline Từ trên 520 đến 600 & 5 & 2,3 & Từ 5 đến 6 người & 90 & 42,1 \\
\hline Trên 600 & 175 & 81,8 & Trên 6 người & 27 & 12,6 \\
\hline \multicolumn{1}{|c|}{ Tổng } & $\mathbf{2 1 4}$ & $\mathbf{1 0 0}$ & Tổng & $\mathbf{2 1 4}$ & $\mathbf{1 0 0}$ \\
\hline
\end{tabular}

Nguồn: Tính toán tì̀ số liệu điều tra

\section{Trang 52}


4.2. Phân tích yếu tố ảnh hưởng tới tình trạng nghèo trong cộng đồng ngư dân ven biển tại tỉnh Ninh Thuận

Để xác định khả năng một hộ rơi vào diện nghèo, nghiên cứu đã sử dụng mô hình hồi quy logit để ước lượng. Trong các biến của mô hình phân tích có hai yếu tố không có ý nghĩa thống kê ở mức ý nghĩa $10 \%$ là biến khoảng cách từ nhà của chủ hộ đến trung tâm chợ và kinh nghiệm trong hoạt động khai thác của chủ hộ. Sau khi loại các biến này và thực hiện phân tích lại, kết quả được thể hiện ở Bảng 3. Kết quả phân tích cho thấy, trong các biến số được xem xét hầu hết các biến số đều không có ý nghĩa thống kê ở mức ý nghĩa $1 \%, 5 \%$ và $10 \%$, ngoại trừ biến số qui mô hộ gia đình, nghề khai thác bằng lưới kéo và thời gian đi học của chủ hộ.

Bảng 3. Kết quả mô hình hồi quy logit về tình trạng nghèo của hộ

\begin{tabular}{|l|c|c|c|c|c|c|c|}
\hline $\begin{array}{c}\text { Biến phụ thuộc: hộ gia đình } \\
\text { nghèo (Hộ nghèo=1) }\end{array}$ & Ký hiệu & $\begin{array}{c}\text { Hệ số } \\
\left(\mathbf{B}_{\mathbf{k}}\right)\end{array}$ & S.E & Wald & Df & Sig. & $\begin{array}{c}\text { Exp } \\
(\mathbf{B})\end{array}$ \\
\hline Qui mô hộ gia đình & QUIMO & 0,580 & 0,160 & 13,177 & 1 & 0,000 & 1,786 \\
\hline Thời gian đi học của chủ hộ & HOCVA_CH & $-0,790$ & 0,328 & 5,793 & 1 & 0,016 & 0,454 \\
\hline Nghề khai thác bằng lưới kéo & NGHE_KEO & $-1,009$ & 0,575 & 3,083 & 1 & 0,079 & 0,364 \\
\hline Hằng số & B $_{0}$ & $-3,133$ & 1,159 & 7,310 & 1 & 0,007 & 0,044 \\
\hline Số quan sát & \multicolumn{7}{|c|}{100,508} \\
\hline -2Log likelihood & \multicolumn{7}{|c|}{0,362} \\
\hline Nagekerke R Square & \multicolumn{7}{|c|}{} \\
\hline
\end{tabular}

Nguồn: Tính toán tù số liệu điều tra

Hệ số của các biến mang dấu âm có nghĩa nếu các yếu tố khác không đổi, việc tăng thêm một đơn vị biến này sẽ làm giảm xác suất rơi vào tình trạng nghèo của hộ. Hệ số của các biến mang dấu dương là những yếu tố làm tăng xác suất rơi vào nghèo đói nếu tăng thêm một đơn vị biến này trong điều kiện tất cả biến còn lại không đổi. Ngược lại những biến có hệ số hồi qui có dấu âm (-) là những biến làm giảm khả năng đó nghèo của hộ gia đình.

Từ hệ số tác động biên (ebk), tỉ lệ nghèo thực tế tại Ninh Thuận trong kết quả điều tra đối với cộng đồng ngư dân này là $10,3 \%$ và các biến số có ý nghĩa trong mô hình hồi qui. Nghiên cứu đã giả định thêm các kịch bản nghèo khác nhau: $10 \%, 20 \%$ và $30 \%$.

Bảng 4. Kết quả mô phỏng về tình trạng nghèo của hộ gia đình ngư dân tại Ninh Thuận

\begin{tabular}{|l|c|c|c|c|c|}
\hline $\begin{array}{c}\text { Biến phụ thuộc: Có phải hộ gia } \\
\text { đình nghèo (Hộ nghèo =1) }\end{array}$ & \multicolumn{3}{|c|}{$\begin{array}{c}\text { Hệ số tác động } \\
\text { biên }\left(\mathbf{e}_{\mathbf{k}}^{\mathbf{k}} \mathbf{)}\right.\end{array}$} & \multicolumn{3}{|c|}{$\begin{array}{c}\text { Xác suất nghèo đói được uoớc tính } \\
\text { khi biến số độc lấp thay đổi một } \\
\text { đơn vị và xác suất ban đầu là: }\end{array}$} \\
\hline Các biến số độc lập: & & 10 & 10,3 & 20 & 30 \\
\hline Quy mô hộ gia đình & 1,786 & 16,56 & 17,02 & 30,87 & 43,36 \\
\hline Thời gian đi học của chủ hộ & 0,454 & 4,80 & 4,95 & 10,19 & 16,29 \\
\hline Nghề lưới kéo (Có $=1)$ & 0,364 & 3,89 & 4,01 & 8,34 & 13,49 \\
\hline
\end{tabular}

Nguồn: Tính toán tì̀ số liệu điều tra của tác giả 
Trong mô hình này, biến quy mô hộ gia đình có ý nghĩa thống kê ở mức ý nghĩa $1 \%$. Biến mang dấu dương, có nghĩa là nếu các yếu tố khác không đổi, việc tăng thêm một thành viên trong hộ gia đình sẽ làm tăng xác suất nghèo đói của hộ, hay nói cách khác nếu qui mô hộ gia đình ngư dân tăng thêm 1 người thì xác suất rơi vào tình trạng nghèo của hộ tăng ở mức $17,02 \%$ so với xác suất nghèo ban đầu là $10,3 \%$.

Biến thời gian đi học của chủ hộ trong gia đình mang dấu âm, có nghĩa là nếu các yếu tố khác không đổi, việc tăng thêm một năm đi học của chủ hộ sẽ làm giảm xác suất nghèo đói của hộ ở mức ý nghĩa $5 \%$. Điều này cũng có nghĩa nếu chủ hộ thêm 1 năm đi học thì xác suất nghèo giảm còn $4,95 \%$ so với tỷ lệ nghèo hiện tại là $10,3 \%$.

Biến nghề lưới kéo có ý nghĩa thống kê ở mức $10 \%$. Hệ số hồi qui của biến này mang dấu âm có nghĩa là nếu trong điều kiện các yếu tố khác không đổi, việc hộ có hoạt động khai thác bằng nghề lưới kéo thì xác suất nghèo giảm còn $4,01 \%$ so với xác suất nghèo ban đầu là $10,3 \%$. Điều này phù hợp với thực tế tại địa phương khi mà tình trạng nguồn lợi thủy sản ven bờ bị suy giảm, việc gia tăng nỗ lực đánh bắt bằng nghề này sẽ đem lại thu nhập tốt hơn cho gia đình của hộ.

Kết quả phân tích đã cho thấy, có ba yếu tố có khả năng làm trầm trọng thêm tình trạng nghèo của hộ, bao gồm: Qui mô hộ gia đình, thời gian đi học của chủ hộ và nghề lưới kéo. Trong đó, qui mô hộ gia đình có khả năng làm cho xác suất rơi vào tình trạng nghèo của hộ cao nhất.

Lập luận một cách tương tự cho các trường hợp khác với giả định ban đầu tỷ lệ hộ nghèo ở mức $10 \%, 20 \%, 30 \%$, cũng cho thấy những yếu tố trên có thể làm giảm hoặc gia tăng tình trạng nghèo của hộ ngư dân ven biển tỉnh Ninh Thuận.

\section{Kết luận và khuyến nghị}

Kết quả nghiên cứu cho thấy, mô hình đã giải thích được $36,2 \%$ sự biến thiên của các biến số nghiên cứu đến khả năng rơi vào tình trạng nghèo của hộ gia đình ngư dân ven biển tại Ninh Thuận. Các yếu tố chính ảnh hưởng tới tình trạng nghèo của hộ bao gồm: quy mô hộ gia đình, thời gian đi học của chủ hộ và hộ làm nghề lưới kéo. Trong các yếu tố trên, qui mô hộ gia đình có ảnh hưởng lớn nhất. Từ kết quả nghiên cứu đã gợi ra một số chính sách nhằm giảm tình trạng nghèo của hộ ngư dân nghề khai thác ven bờ tại khu vực này, như sau:

Thứ nhất, giảm qui mô hộ gia đình thông qua chính sách dân số và các chương trình kế hoạch hóa gia đình. Từ kết quả phân tích cho thấy, qui mô hộ gia đình có ảnh hưởng mạnh nhất đến tình trạng nghèo của hộ gia đình. Hầu hết các hộ ngư dân ven biển tỉnh Ninh Thuận nằm trong đối tượng nghèo luôn có qui mô hộ lớn và số nhân khẩu cao hơn những hộ khác bởi vì hộ nghèo sinh đẻ không có kế hoạch do trình độ học vấn thấp dẫn đến thiếu hiểu biết, những quan niệm không đúng về việc sinh đẻ, hay muốn sinh con để có thêm lao động mà đẻ quá dày, quá nhiều. Đây cũng là chính sách mà Ninh Thuận đang theo đuổi (UBND tỉnh Ninh Thuận, 2013b). Chính vì vậy, một số giải pháp quan trọng cần hướng đến nhằm hạn chế qui mô hộ gia đình, như: (i) tăng cường các biện pháp để giảm mức sinh thực hiện song song với các chương trình xóa đói giảm nghèo tại địa phương. Cần có nhiều chương trình phổ biến kiến thức và khuyến khích sử dụng các biện pháp tránh thai, đặc biệt là đối với những hộ ngư dân ở vùng xa, những hộ có học vấn thấp và những hộ nghèo; (ii) cần có những biện pháp tuyên truyền thiết thực hơn để làm thay đổi quan niệm sinh đẻ, thích đông con hay thích con trai hơn con gái; (iii) chính quyền địa

\section{Trang 54}


phương cùng với Mặt trận, Hội Phụ nữ, Hội Nông dân tạo cơ hội cho người phụ nữ tiếp cận với thế giới bên ngoài, nhằm nâng cao hiểu biết, nhất là những hiểu biết về kế hoạch hóa gia đình và những biện pháp bảo vệ sức khỏe sinh sản cho phụ nữ.

Thứ hai, giáo dục là quốc sách hàng đầu, là cơ sở tạo nên nguyên khí của quốc gia, vì vậy cần thêm những chính sách về giáo dục mang tính thiết thực hướng tới những cộng đồng ngư dân, đặc biệt là những hộ nghèo. Kết quả phân tích cho thấy, thời gian đi học của chủ hộ có tác động tích cực tới việc cải thiện tình trạng nghèo của hộ gia đình ngư dân. Điều này càng khẳng định tầm quan trọng của giáo dục trong chính sách giảm nghèo hiện nay. Vì vậy, chính quyền địa phương cần: (i) đẩy mạnh công tác tuyên truyền về tầm quan trọng của giáo dục và đào tạo để cộng đồng nhận thấy rằng giáo dục luôn có ảnh hưởng quan trọng trong tương lai; (ii) giảm hoặc miễn học phí và miễn một số khoản đóng góp cho con em các hộ nghèo, cấp sách giáo khoa miễn phí cấp những đầu sách quan trọng hoặc cho mượn học xong trả lại. Đối với những người lớn tuổi cần tạo điều kiện để họ tham gia các chương trình khuyến ngu, khuyến nông để có cơ hội chuyển sang nghề khác, như làm dịch vụ thủy sản, buôn bán nhỏ... khi họ không còn đủ sức khỏe để tham gia vào hoạt động khai thác trực tiếp.

Thứ ba, chuyển đổi nghề cho các hộ ngư dân ven biển tỉnh Ninh Thuận trong giai đoạn hiện nay là hết sức quan trọng. Kết quả điều tra và phân tích cho thấy đa số những hộ ngư dân hoạt động trong nghề khai thác hải sản là những hộ nghèo, số ít nằm trong diện cận nghèo và đặc biệt là những hộ hoạt động trong nghề lưới kéo. Vấn đề cần đặt ra ở đây là phải chuyển đổi nghề khai

\section{TÀI LIÊUU THAM KHẢO}

[1]. Chính phủ (2003), Chiến luợc toàn diện về tăng truởng và xóa đói giảm nghèo giai đoan 2001 - 2010, Hà nội thác ven bờ kém hiệu quả và ảnh hưởng đến nguồn lợi hải sản sang những ngành nghề khác. Việc chuyển đổi này cũng là hướng đi đúng và phù hợp với chủ trương cắt giảm năng lực tàu thuyền có công suất nhỏ vừa tạo điều kiện để những hộ nghèo cải thiện đời sống của mình. Mặt khác, trong bối cảnh nghề cá của cả nước đang thực hiện chủ chương vươn xa và đặc biệt trong tình hình biển đảo hiện nay của nước ta chiến lược phát triển biển Việt Nam đang trong quá trình được triển khai nhằm bảo vệ và phát huy lợi thế của một quốc gia có biển, làm giàu lên từ biển, đảm bảo được chủ quyền lãnh hải của đất nước thì việc chuyển đổi những nghề khai thác ven bờ này là ưu tiên hàng đầu. Một số giải pháp và bước đi phù hợp, chú trọng nâng cao hiệu quả của những nghề chuyển đổi và sớm ổn định được đời sống của các hộ ngư dân này, cụ thể như sau: (i) tuyên truyền thường xuyên về tình trạng suy giảm nguồn lợi, chủ chương cắt giảm năng lực tàu thuyền tại khu vực ven bờ để những hộ ngư dân hoạt động trong các nghề khai thác thuộc khu vực này nhận thức được sự cần thiết và tầm quan trọng của việc chuyển đổi; (ii) chú trọng những hộ chuyển từ các nghề khai thác ven bờ sang các nghề khai thác xa bờ.

Mặc dù nghiên cứu đã cố gắng để thu thập và điều tra dữ liệu về thực trạng nghèo của các hộ gia đình ngư dân ven biển tỉnh Ninh Thuận. Tuy vậy, mẫu điều tra còn nhỏ so với số lượng lớn hộ gia đình ngư dân tại địa phương. Bên cạnh đó, việc sử dụng quan điểm và chuẩn nghèo của Chính phủ để tính toán các chỉ số nghèo đói mới phản ảnh một khía cạnh nghèo về thu nhập. Sẽ là đầy đủ và khái quát hơn nếu sử dụng chỉ số nghèo đa chiều để đánh giá tình trạng nghèo của hộ ngư dân tại khu vực này. Đây sẽ là hướng nghiên cứu tiếp theo.

[2]. Chính Phủ (2007), Quyết định của Thủ Tuớng Chính Phủ số 20/2007/QĐ-TTg về việc phê duyệt chuoong trình mưc tiêu quốc 
gia giảm nghèo giai đoạn 2006 - 2010, Hà nội.

[3]. Chính Phủ (2011), Quyết định của Thủ Tuoóng Chính Phủ số 09/2011/QĐ-TTg về việc ban hành chuẩn hộ nghèo, hộ cận nghèo áp dụng cho giai đoạn 2011 - 2015, Hà nội.

[4]. Jonathan Houghton, Dominique và các tác giả khác (1999), Hộ gia đình Việt Nam nhìn qua phân tích định luợng, Nhà xuất bản Chính trị Quốc gia, Hà Nội.

[5]. Jonathan Haughton, Shahidur R. Khader (2009), Handbook on Poverty and Iniquality, World Bank, Washington, D.C.

[6]. Nguyễn Trọng Hoài \& đồng nghiệp (2006), Nghiên cứu úng dụng các mô hình kinh tế lương trong phân tích các nhân tố tác động nghèo đói và đề xuất giải pháp xóa đói giảm nghèo (Đề tài trọng điểm cấp Bộ năm 2004, MS: B2004 - 22- 60TĐ), Trường Đại học Kinh tế Tp. Hồ Chí Minh.

[7]. Đinh Phi Hổ (2013), Phurong pháp nghiên cưu định luợng và nhũng nghiên cưu thưc tiễn trong kinh tế phát triển - nông nghiệp, Nhà xuất bản Phương Đông.

[8]. Phạm Hồng Mạnh (2011a), Những giải pháp giảm nghèo trong hộ gia đình ngu dân nghề khai thác ven bờ tại khu vực Nam Trung Bộ, Tạp chí Kinh tế sinh thái, (số 4), tr. $117-127$.

[9]. Phạm Hồng Mạnh (2011b), Nguyên nhân và giải pháp giảm nghèo trong cộng đồng ngư dân nghề khai thác hải sản ven bờ tại Khánh Hòa, Tạp chí Khoa hoc Công nghệ Thủy sản, (số 2), tr. 03-10.

[10]. Ngân hàng thế giới (2012), Báo cáo đánh giá nghèo Việt Nam 2012: Khởi đầu tốt, nhung chua phải đã hoàn thành - Hà Nội.
[11]. UBND tỉnh Ninh Thuận (2013a), Báo cáo 257/BC-UBND ngày 03/12/2013 về Tình hình thục hiện nhiệm vu kinh tế - xã hội năm 2013; kết quả 3 năm thục hiện kế hoach 5 năm 2011-2015 và Phwong huoóng, nhiệm vu năm 2014-2015 và năm 2014, Ninh Thuận.

[12]. UBND tỉnh Ninh Thuận (2013b), Quyết định số 205/2010/QĐ-UBND ngày 04/3/2011 về việc Phê duyệt đề án kiểm soát dân số vùng biển và ven biển giai đoạn tỉnh Ninh Thuận 2010 - 2020, Ninh Thuận.

[13]. UBND tỉnh Ninh Thuận (2014), Cổng thông tin điện tử tỉnh Ninh Thuận: Điều kiện tụ nhiên và xã hội, truy cập từ http://www.ninhthuan.gov.vn/Pages/Dieukien-tu-nhien1.aspx ngày 26/9/2014.

[14]. World Bank (2005), Introdution to poverty analysis, World Bank, Washington D.C.

[15]. Bảng xếp hạng mức độ giàu nghèo của 63 tỉnh thành phố, bạn đang ở tỉnh nào, xếp hạng các tỉnh thành tại Việt Nam, truy cập từ: http://imta.edu.vn/bang-xep-hang-mucdo-giau-ngheo-cua-63-tinh-thanh-pho-bandang-o-tinh-nao.html\#ixzz3OgmEwile

[16]. World Bank (2014), World Bank Updates Poverty Estimates for the Developing World,

http://econ.worldbank.org/WBSITE/EXTE RNAL/EXTDEC/EXTRESEARCH/0,,cont entMDK:21882162 pagePK:64165401 pi PK:64165026 theSitePK:469382,00.html, truy cập ngày 23/08/1014.

\section{Trang 56}

